\title{
Effect of injection timing on particle size distribution of a diesel engine fueled with biodiesel-diesel blends
}

\author{
Theeranan Phatai ${ }^{1}$, Raschanon Kumpiranon ${ }^{1}$, Kritsana Ounnarut ${ }^{1}$, Nattapol Pongrasri ${ }^{1,2}$, Pubet Meenaroch ${ }^{1}$ and \\ Pomprab Sriumpunpuk ${ }^{1,2 *}$ \\ ${ }^{1}$ Department of Mechanical and Automotive Engineering Technology (MAet), Faculty of Engineering and Technology, \\ King Mongkut's University of Technology North Bangkok (Rayong Campus), Nonglalok, Bankhai, Rayong 21120, Thailand. \\ ${ }^{2}$ Research Centre for Combustion Technology and Alternative Energy (CTAE), Science and Technology Research Institute, \\ King Mongkut's University of Technology North Bangkok, Bangkok 10800, Thailand.
}

\begin{abstract}
The purpose of this study is to investigate injection timing affected particle size distribution of a diesel engine fueled with biodiesel/diesel blends. The biodiesel blending ratios include 7, 10 and $20 \%$ vol. The experiments were operated at engine speed 1,500 rpm under 25, 50 and $75 \%$ engine loads and two different injection timing (25.5 CAD BTDC and 27.5 CAD BTDC). The effects of biodiesel addition and injection timing on the changes in black smoke and particle size distribution were discussed. Results showed that the standard injection timing for the addition of biodiesel, especially for $20 \%$ biodiesel blended with diesel fuel (B20) had a significant effect of increasing particle concentration and thus black smoke emission. The advanced injection timing for B20 could improve combustion efficiency and reduce small particles emission in nucleation-mode (Dp $5-50 \mathrm{~nm}$ ) and particles in accumulation-mode (Dp 50-1,000 $\mathrm{nm}$ ) became the smaller particle size, compared to standard and retarded injection timing. Moreover, the oxygen content in biodiesel could improve combustion efficiency and reduce the emission but it is necessary to modify the engine especially fuel injection timing.
\end{abstract}

Keyword. Compression ignition engine; Particle size distribution; Biodiesel

\section{Introduction}

Nowadays, the popularity of compression ignition engines is growing in both the transportation and power generation sectors because of its high efficiency, fuel economy and durability compared to spark ignition engines [1-2]. Due to the declining trend of fossil energy sources in the future, it is necessary to find alternative energy that can be used instead of diesel fuel [3-4]. In addition, air pollution problems arise from combustion process of compression ignition engines, especially particulate matter (PM). Most particulate matter consists of solid carbon particles absorbing organic matter from the fuel, lubricants and sulfates in the exhaust particles, all of which are produced by the combustion of diesel fuel [5]. Diesel combustion with a C-C bond in the thick mixture region forms very small particles which can be agglomerated with other organic matter to become the larger particle size. Over the past few decades, researchers have studied the dust particle distribution. The diesel engine particulates in the exhaust gas are classified according to the particle diameter, which contains nucleation-mode particles (diameter of the particle, $5 \mathrm{~nm}<\mathrm{D}_{\mathrm{p}}<50 \mathrm{~nm}$ ), accumulation-mode particles ( $50 \mathrm{~nm}<\mathrm{D}_{\mathrm{p}}<1,000 \mathrm{~nm}$ ) and coarse-mode particles $\left(D_{p}>1,000 \mathrm{~nm}\right)[6]$. These particles can impact on the human respiratory system, so it is important to find solutions to reduce the amount of particulate matter produced by the combustion of diesel fuel in compression ignition engines.

Previous research examines that oxygen-rich diesel can promote sufficient oxygen for combustion and increase combustion efficiency, resulting in reduced soot $[2,7]$. Biodiesel, one of the most widespread renewable fuels, can be substituted for diesel without minor engine modifications. The process for biodiesel production is the transesterification of triglycerides of vegetable oils, animal fats and waste cooking oils [4]. The study of biodiesel properties found that biodiesel has similar properties to diesel. The advantages of using biodiesel over diesel are its higher cetane numbers and high oxygen content, resulting in a reduction in the amount of combustion dust. Chiatti et. al., [8] compared the results of the particles size distributions on an unmodified diesel engine using ultra-low sulfur diesel (ULSD) blended

\footnotetext{
* Corresponding author: pomprab.s@eat.kmutnb.ac.th
} 
with biodiesel produced from waste cooking oil at ratios of 20 and $40 \%$ to standard ultra-low sulfur diesel fuel.

The total particle number concentration results showed that when using both types of biodiesels, the overall particle concentration decreased compared to the ultra-low sulfur diesel in all test conditions. This is due to the high cetane number of the biodiesel, which shortens the ignition delay, as a result, a longer combustion of the mixed control range. The oxygen content of the biodiesels also promotes efficient combustion and contributes to soot oxidation, particularly during high engine loads. The results of the particle number size distributions at engine operating conditions with high load and speed explain that as the ratio of biodiesel increases, the number of very fine particles (nucleation-mode particles, DP $<50 \mathrm{~nm}$ ) increases. On the other hand, the number of accumulation and coarse-mode particles decreases compared to the standard diesel. This means that the biodiesels make the size of particulate matter to become smaller. Agarwal et al. [9] studied the effect of increasing biodiesel ratio blended with diesel. They found that when increasing the biodiesel content at $20 \%$ and $100 \%$, the benzene soluble organic fraction (BSOF) in the exhaust composition is increased compared to the exhaust from the diesel. The BSOF is the primary component of particulate matter and directly affects particle size. In contrast, oxygen content in biodiesel can reduce soot generation, especially solid carbon particles, and results in an increasing number of $30-40 \mathrm{~nm}$ particles. Likewise, Puzun et al. [10] reported that when using biodiesel from rapeseed oil, the particles in the range of nucleation mode particles increase while particles larger than $50 \mathrm{~nm}$ (accumulation-mode particles) reduce.

Compared to the particulate matter in the diesel exhaust, it had the single peak distribution dominating accumulation-mode particles. From the previous research, most of the experiments were conducted without any engine modifications. Because the fuel properties have been changed, it resulted in certain engine operating conditions causing an increase in emissions especially the number of particles in the exhaust. Therefore, it is necessary to study the minor engine modifications in order to accommodate the use of biodiesel and diesel fuel to be more efficient and reduce emissions. Kim et al. [11] investigated the effect of biodiesel and injection timing on ignition delay and engine emission. The results shown that advance injection timing can be improved the maximum cylinder pressure and good for premixed combustion period. Advance injection timing also reduced a number of particles matter due to evaporation characteristic of fuel better than retard injection timing. It is resulted in high temperature and pressure of combustion. Reddy et al. [12] are investigated the effect of waste mango seed biodiesel at different injection timing. The results shown that the brake thermal efficiency in high proportion biodiesel is reduce when compare with diesel fuel at
STD injection timing. It is led to increase the black smoke. However, the advance injection timing for 2 CAD is applied to the fuel injection system. The effect of advance injection timing shown the high efficiency of combustion and enhancement in fuel and air mixing effected to good combustion and low smoke emission.

In current study, the PM emission of conventional diesel fuel and bio diesel/diesel blends were tested on single cylinder diesel engine. The effect of biodiesel blending ratios and injection timing on total particles concentration and particle number size distribution were discussed by using a particle size spectrometer. Smoke emission was analyzed using smoke meter.

\section{Experimental apparatus}

\subsection{Engine test rig}

The experimental engine in this study was a single cylinder, four strokes, water cooled, spherical type combustion system diesel engine and the engine specifications are shown in Table 1. The engine speed and engine load were controlled by asynchronous motor engine dynamometer (Gunt Hamburg CT 110). Exhaust, air inlet and fuel temperature were measured by type $\mathrm{K}$ thermocouples. The opacity of black smoke emission was measured by Horiba Mexa-600s opacimeter. The total number and particle size distribution were measured by engine exhaust particle size spectrometer (TSI EEPS 3090), which can measure diameter range is from $5.6-560 \mathrm{~nm}$. Dekati TI-1000 double stage diluter which total dilution ratio was 73.27:1 (8.56 each diluter) used for dilute exhaust concentration before the particles pass through the EEPS. The First stage diluter and air dilution were heated to $190^{\circ} \mathrm{C}$ for avoid condense of water and hydrocarbon in exhaust. Time duration for collecting data of particle size distribution was $60 \mathrm{~s}$. Schematic diagram shows in Fig. 1.

Table 1. Specifications of engine

\begin{tabular}{ll}
\hline Item & Specification \\
\hline Model & Kubota EA300 E2 NB1 \\
Type & 4 Stroke Diesel engine \\
Number of cylinder & 1 \\
Bore/Stroke & $75 \mathrm{~mm} / 70 \mathrm{~mm}$ \\
Displacement volume & $0.309 \mathrm{~L}$ \\
Combustion system & Spherical type \\
Max. Output (kW) & $5.2 \mathrm{~kW} @ 3000 \mathrm{RPM}$ \\
Injection timing & $25.5 \mathrm{CAD}$ BTDC \\
Fuel injection system & Mechanical \\
\hline
\end{tabular}




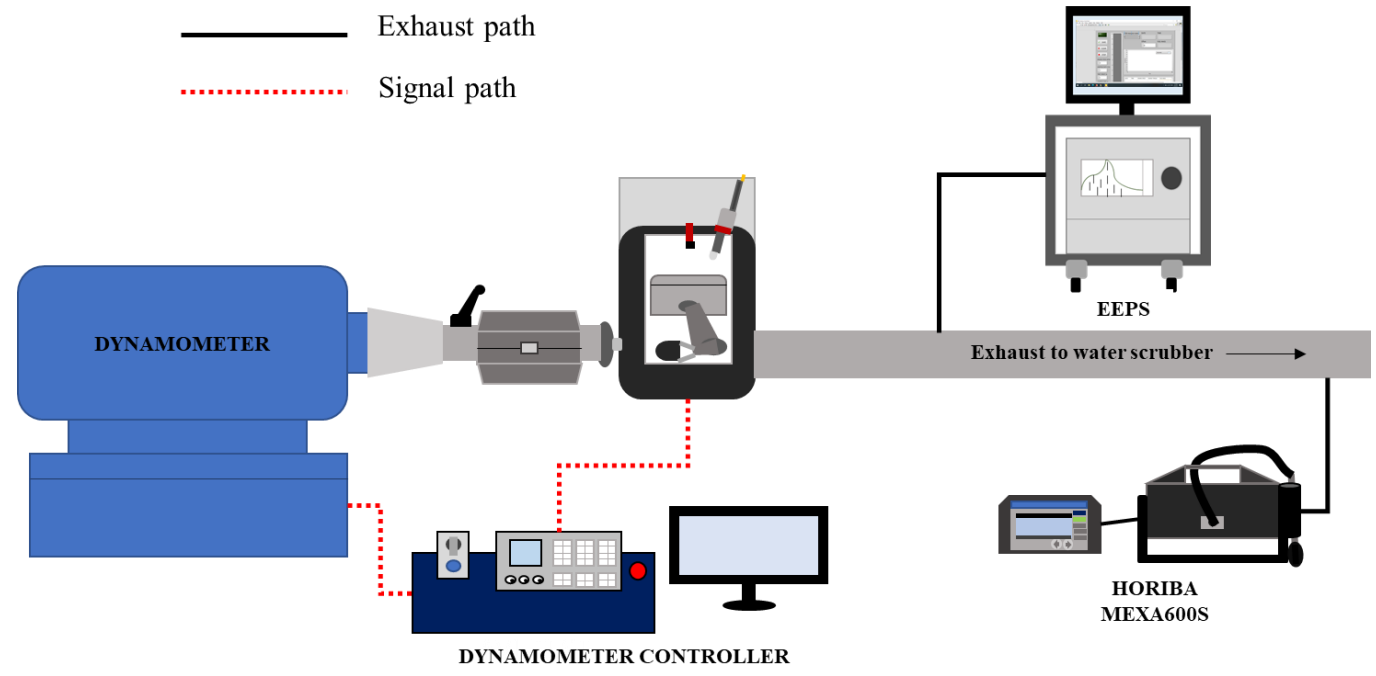

Fig. 1. Schematic diagram of the experimental setup.

\subsection{Fuels}

Three different fuels were a commercial diesel fuel (93\% diesel and 7\% Vol. bio-diesel blends, B7), blend of 90\% diesel with $10 \%$ bio-diesel and $80 \%$ diesel with $20 \%$ bio-diesel, labelled as B7, B10 and B20, respectively. The heating value of all fuels were evaluated by bomb calorimeter (IKA C6000). The heating value of the test fuels are given in Table 2.

Table 2. Heating value of the test fuels

\begin{tabular}{lc}
\hline Fuel & Heating value (J/g) \\
\hline Commercial diesel (B7) & 45,352 \\
Biodiesel (B100) & 41,240 \\
B 10 & 44,386 \\
B 20 & 44,145 \\
\hline
\end{tabular}

\subsection{Test conditions and procedure}

The effect of biodiesel blends (B7, B10 and B20) on smoke emission, total number of particle concentration and particulate number size distribution were analyzed under engine speed of 1,500 RPM and engine loads were set at $25 \%, 50 \%$ and $75 \%$ of engine full load without exhaust gas recirculation (EGR) system. The injection timing was set at 25.5 crank angle degree before top dead center (CAD BTDC) as standard injection timing and advance injection timing for $2 \mathrm{CAD}$ (27.5 CAD BTDC) was considered.

The temperatures of engine coolant and engine oil were controlled in ranges of $85 \pm 3^{\circ} \mathrm{C}$ and $87 \pm 2^{\circ} \mathrm{C}$ respectively $[10,13]$. The engine was run for $15 \mathrm{~min}$ when the fuel was changed to new fuel to avoid the previous fuel remaining in the system. The data of smoke emission and heating value of fuels were recorded three times. The results of particle size distribution were recorded 60 times in a minute and their average values were taken for the discussions.

\section{Results and discussion}

\subsection{Effect of biodiesel blends fuel on smoke emission and particulate size distribution}

In this section, the results of smoke emission and particle size distribution were considered under three different engine loads of 1,500 RPM engine speed. Fig. 2 shows that the addition of biodiesel into diesel fuel had a greater effect on smoke emissions and when the engine load increased, the effect of smoke emissions also increased significantly. Compared with conventional diesel (B7), the opacity of smoke emission of B10 and B20 increased by $80.3 \%$ and $204.6 \%$ respectively at $75 \%$ engine load condition. Because of the high viscosity of biodiesel, when biodiesel was injected to combustion chamber, it was difficult to atomize and evaporate. This resulted in a longer ignition delay [9], which promoted rich region of fuel spray and soot precursor.

Fig. 3 presents effect of biodiesel blending ratio on particulate number size distribution at $25 \%$ (3a), $50 \%$ (3b) and $75 \%(3 c)$ engine load of 1,500 RMP engine speed and standard injection timing. From Fig 3a. at light engine load $(25 \%)$, the results demonstrate that particle concentration and size distribution present in two curves. The first peak was at particle diameter $10-$ $20 \mathrm{~nm}$ as well as the second peak was $50 \mathrm{~nm}$ represented in nucleation-mode particle. Fig. $3 \mathrm{~b}$, at medium engine load, shows a double peak which occurred in nucleationmode particles. An increase in the biodiesel ratio, especially in the high ratio of biodiesel (B20), resulted in an increase in concentration of particles due to high viscosity of fuel deteriorated the fuel atomization, lager droplet size and longer ignition delay compares with diesel fuel [8]. 


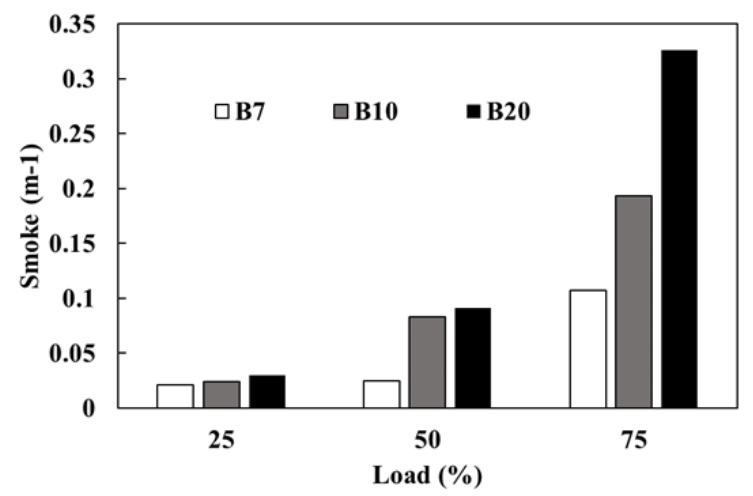

Fig. 2. Effect of biodiesel blending ratio on smoke emission for various engine loads.
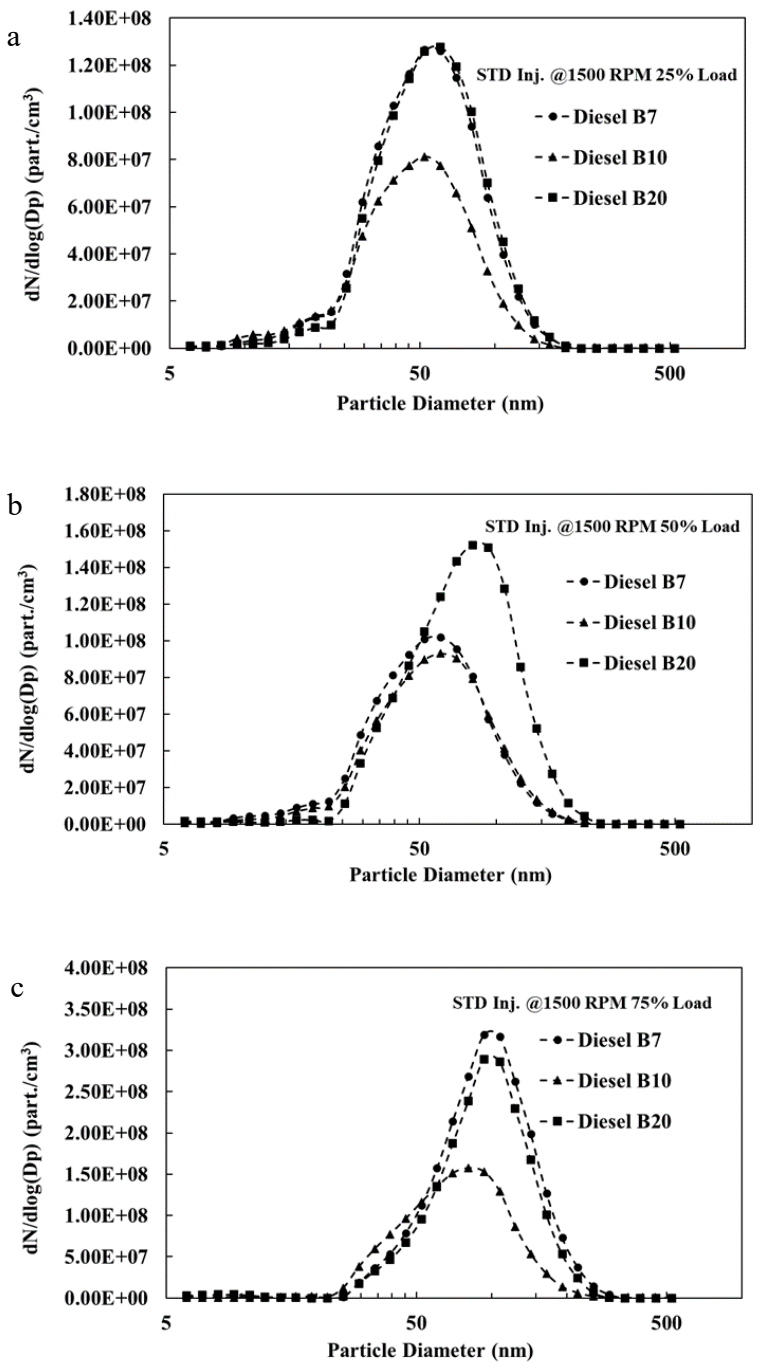

Fig. 3. effect of biodiesel blending ratio on particulate number size distribution.

Fig. 3c presents the variation of particles concentration at high engine load $(75 \%)$. The particles were shown as a single peak in accumulation-mode at $100-150 \mathrm{~nm}$ due to the reduction of air-fuel mixing and incomplete combustion form rich combustion resulting in higher soot formation and concentration [8]. On the other hand, the diameter of particles was gradually decreased with addition of biodiesel into diesel fuel because the higher oxygen content of biodiesel promoted the soot oxidation and high percentage of benzene soluble organic fraction (BSOF) in biodiesel fuel released with engine exhaust. These particles, consisting of organic products, contribute to the increase of nucleation mode particles [9].

Fig. 4 shows the total number concentration of particles from conventional diesel and biodiesel blends. The results showed that $\mathrm{B} 10$ had a reduction in particle concentration compared to B7 fuel because its higher oxygen ratio in molecules encouraged the combustion efficiency and can reduce particle emission. It also improved diffusion combustion and promoted the post oxidation process of solid carbon, which formed during combustion. On the other hand, when the proportion of the biodiesel was $20 \%$ (B20), there was an increase in the total particle number concentration, especially particles in nucleation mode [9]. This means that the use of this biodiesel proportion had a greater effect on the total concentration than accumulation-mode particles because of the highly change of physical properties in B20 fuel such as high viscosity and density.

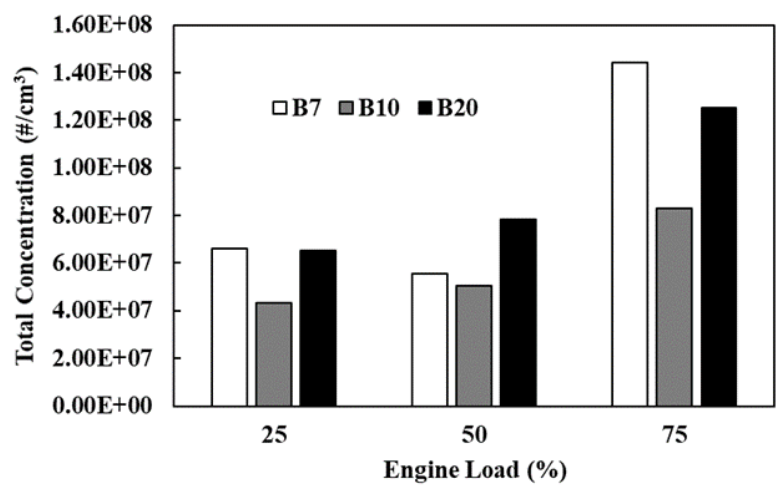

Fig. 4. Effect of biodiesel blending ratio on total particulate number concentration.

The increment of biodiesel blending ratio (B20) resulted in high smoke emission and high particles concentration. To improve the combustion performance and reduce smoke and PM emission, it is necessary to modify the engine such as injection timing. An influence of advance injection timing for 2 CAD BTDC will discuss in next chapter.

\subsection{Effect of injection timing and biodiesel blends fuel on smoke emission and particulate size distribution}

This section shows the results of smoke emission, total concentration, particulate size distribution of B20 fuel with different engine load and advance injection timing (27.5 CAD BTDC) versus standard injection timing (25.5 CAD BTDC). Fig. 5 shows that advance injection timing led to decrease the opacity of black smoke by 
$53.3 \%, 28.5 \%$ and $44.4 \%$ with $25 \%, 50 \%$ and $75 \%$ engine load, respectively. Generally, soot formation in combustion process is form due to uneven mixture of air and fuel. Also, the high viscosity of biodiesel is difficult to fuel atomization and evaporation, that effect to longer ignition delay. The advance injection timing can increase air-fuel mixing efficiency, which decrease rich mixture in diffusion combustion stage $[1,12]$.

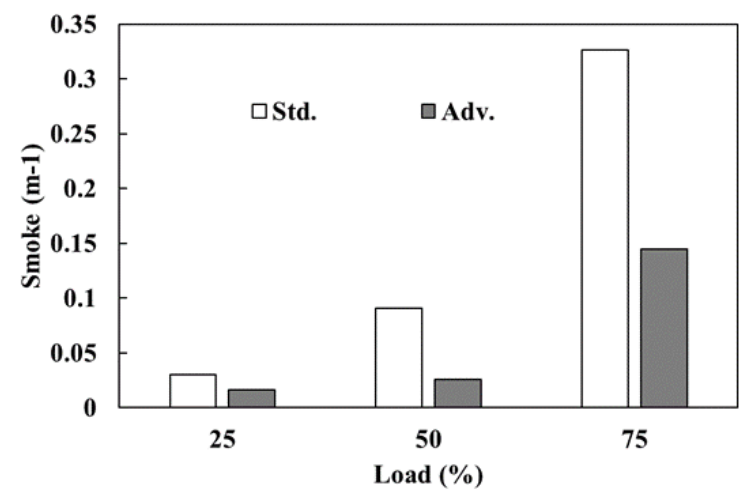

Fig. 5. Effect of advance injection timing with B20 on smoke emission for various engine loads.

The particulate number size distribution of advance and standard injection with B20 fuel in various engine load are shown in Fig.6. It is obviously shown that at low and middle engine load, particle size distributions occurred the bimodal structure in nucleation-mode and accumulation-mode and particles in high engine transformed to accumulation-mode only. Fig. 6a showed advance injection timing had no significant effect on smallest particles (nucleation-mode), while accumulation-mode particles decreased and also reduced peak of particle concentration from $1.3 \mathrm{E}+08$ to $8.0 \mathrm{E}+07$ part. $/ \mathrm{cm}^{3}$. Fig. $6 \mathrm{~b}$ showed particulate number size distribution with $50 \%$ engine load. The trend of peak and distribution of particles was not significant different compared to $25 \%$ engine load. In the meantime, advance injection timing affected to accumulation mode particles reduced, and the peak area shifted to the smaller particle size. This is due to the sufficient atomization of fuel when it is injected into combustion chamber and the longer air-fuel mixing time before combustion compared to standard injection timing [11-12]. The high engine load (75\%) in Fig. 6c presents single peak particles size distribution occurred in accumulation mode only. When comparing this particle size distribution result to low and middle load, it was found that the particle sizes generated by high engine loads were larger.

Fig. 7 shows the total number concentration of particles from B20 exhaust in standard and advance injection timing. With the advance injection timing, the proportion of particles concentration was significantly decreased, which is obtained by particle size distribution in Fig. 6. Advance injection timing can reduce total number concentration by $35.5 \%, 35.1 \%$ and $44.5 \%$ with $25 \%, 50 \%$ and $75 \%$ engine load, respectively. The reason for the decrease in particles concentration, especially accumulation-mode particles, is that the B20 fuel with advance injection timing has longer time to have good evaporation and atomization characteristics. On the other hand, the delayed fuel injection increases the combustion duration and affects more the collision and coagulation time to increase accumulation particles [11, 13-14].
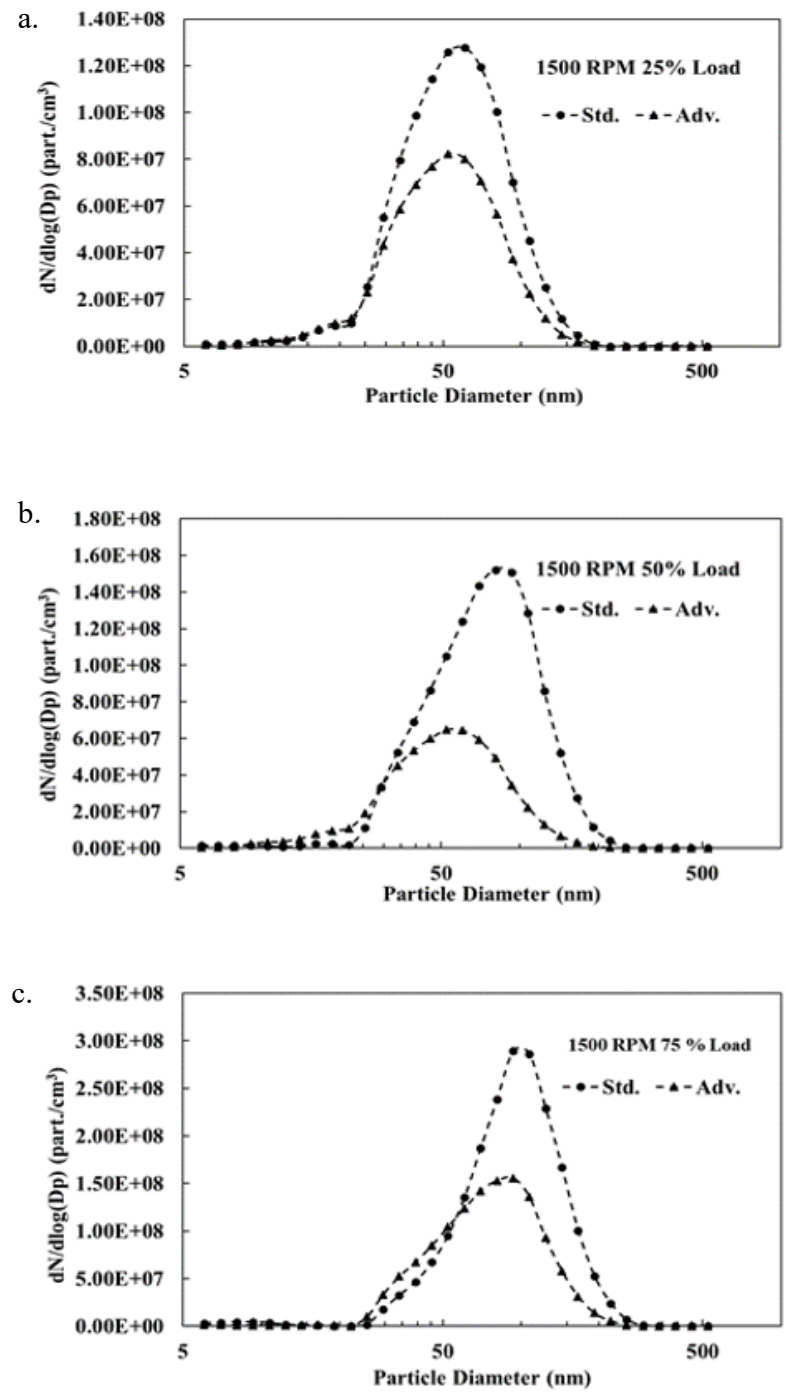

Fig. 6. Effect of injection timing on particulate number size distribution.

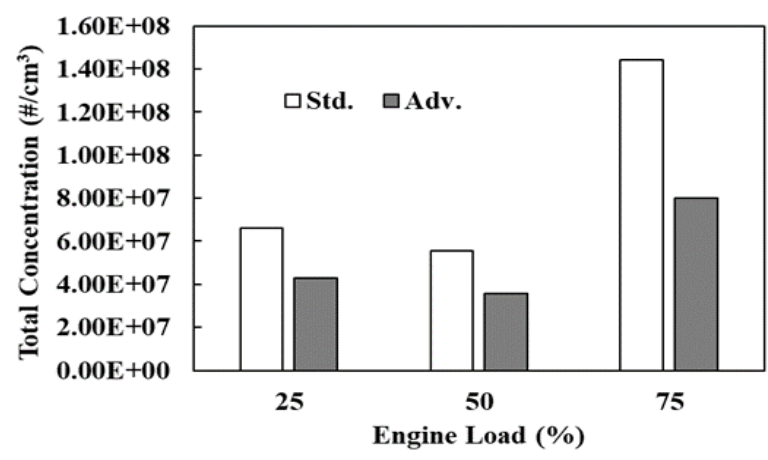

Fig. 7. Effect of injection timing on total particulate number concentration. 


\section{Conclusions}

In current study, the smoke emission and the particle size distribution of exhaust were carried out on a single cylinder mechanical diesel engine with biodiesel blends at various engine loads and injection timing. The main results are concluded as follows:

Biodiesel/diesel blends can effectively reduce the smoke emission and particle size distribution. On the other hand, the increasing proportion of biodiesel (B20) results in changes in the properties of fuel such as viscosity and cetane number, which trends to increase the opacity of black and high concentration of particles in exhaust. B10 is appropriate fuel for this experiment engine due to its higher oxygen content than conventional diesel fuel, which contributes to selfoxygen supply during combustion, especially in diffusion combustion phase. Due to the high biodiesel blends (B20) with advance injection for $2^{\circ} \mathrm{CA}$, the particle distribution moves towards the direction of small particle size, and the ratio of accumulation-mode particles are decreased. The different engine loads show different particle size distributions. For low and middle engine, the peak of particles concentration appears a bimodal curve (nucleation and accumulation mode particle) and converts to single curve in accumulation particle. Finally, the trend shifts to larger particle sizes with high engine loads.

Future investigations are necessary to validate with the effect of high proportion of biodiesel or other fuel additive blends with diesel fuel in commercial diesel engine such as electric control common rail diesel engine with after treatment system on performance and emission characteristic.

\section{Acknowledgement}

The equipment of this work was supported by the Automotive Performance Testing Laboratory (Enhancement of Safety Practice of Research Laboratory in Thailand, ESPRel No. 2-0870-000-3), Faculty of Engineering and Technology, King Mongkut's University of Technology North Bangkok (Rayong Campus) and was funded by the Special Project Fund, King Mongkut's University of Technology North Bangkok. We would like to express our great appreciation for their valuable sponsorship.

\section{References}

1. A.K. Agarwal, T. Gupta, P.C. Shukla, A. Dhar, Particulate emissions from biodiesel fuelled CI engines, Energy conversion and management, 94, (2015): 311-330

2. J. Liu, Z. Liu, L. Wang, P. Sun, H. Ma, P. Wu, Effects of PODE/diesel blends on particulate matter emission and particle oxidation characteristics of a common-rail diesel engine, Fuel processing technology, 212 (2021): 106634
3. L. Geng, Y. Xiao, S. Li, H. Chen, X. Chen, Effects of injection timing and rail pressure on particulate size-number distribution of a common rail DI engine fueled with fischer-tropsch diesel synthesized from coal, Journal of the energy institute, 95 (2021): 219-230

4. M. Hajbabaei, G. Karavalakis, K.C. Johnson, J. Guthrie, A. Mitchell, T.D. Durbin, Impacts of biodiesel feedstock and additives on criteria emissions from a heavy-duty engine, Fuel processing technology, 126 (2014): 402-411

5. D.B. Kittelson, Engine and nanoparticles: A review, Journal of aerosol science, 29 (1998): 575588

6. J. Schneider, N. Hock, S. Weimer, S. Borrmann, U. Kirchner, R. Vogt, V. Scheer, Nucleation particles in diesel exhaust: Composition inferred from in situ mass spectrometric analysis, Environmental science \& technology, 39 (2005): 6153-6161

7. J. Liu, J. Yang, P. Sun, W. Gao, C. Yang, J. Fang, Compound combustion and pollutant emissions characteristics of a common-rail engine with ethanol homogeneous charge and polyoxymethylene dimethyl ethers injection, Applied energy, 239 (2019): 1154-1162

8. G. Chiatti, O. Chiavola, F. Palmieri, Impact of waste cooking oil in biodiesel blends on particle size distributions from a city-car engine, Journal of the Energy Institute, 91 (2018): 262-269

9. A.K. Agarwal, T. Gupta, A. Kothari, Particulate emissions from biodiesel vs diesel fuelled compression ignition engine, Renewable and Sustainable Energy Reviews, 15 (2011): 32783300

10. A. Puzun, S. Wanchen, L. Guoliang, T. Manzhi, L. Chunjie, C. Shibao, Characteristics of Particle Size Distributions About Emissions in A Common-rail Diesel Engine with Biodiesel Blends (2011 2nd International Conference on Challenges in Environmental Science and Computer Engineering, Haikou, 2011)

11. H.J. Kim, S. Jo, J.T. Lee, S. Park, Biodiesel fueled combustion performance and emission characteristics under various intake air temperature and injection timing conditions, Energy, 206 (2020): 118154

12. S.R. Reddy, G. Murali, A.A. Shaik, V.D. Raju, M. B. S. S. Reddy, Experimental evaluation of diesel engine powered with waste mango seed biodiesel at different injection timings and EGR rates, Fuel, 285 (2021): 119047

13. L. Xinling, X. Zhen, G. Chun, H. Zhen, Effect of injection timing on particle size distribution from a diesel engine, Fuel, 134 (2014): 189-195

14. T. Wang, J. Liu, P. Sun, Q. Ji, W. Gao, C. Yang, Influence of injection parameters on combustion, gaseous emissions and particle size distribution of a CRDI diesel engine operating with PODE/diesel blends, Fuel, 281 (2020): 118733 